\title{
Nutritional status of Tunisian adolescents: associated gender, environmental and socio-economic factors
}

\author{
Hajer Aounallah-Skhiri ${ }^{1,2}$, Habiba Ben Romdhane ${ }^{1}$, Pierre Traissac $^{3}$, \\ Sabrina Eymard-Duvernay ${ }^{3}$, Francis Delpeuch ${ }^{3}$, Noureddine Achour ${ }^{1}$ and \\ Bernard Maire ${ }^{3, *}$ \\ ${ }^{1}$ Institut National de la Santé Publique (INSP), 5-7 rue Khartoum, Tunis, Tunisia: ${ }^{2}$ Doctoral School 393, \\ Public Health: Epidemiology and Biomedical Information Sciences, Université Pierre et Marie Curie, Paris, \\ France: ${ }^{3}$ Institut de Recherche pour le Développement (IRD), UR 106 (Nutrition, Food, Societies), WHO \\ Collaborating Centre for Nutrition, 911 Av. d'Agropolis, BP 64501, F-34394 Montpellier Cedex 5, France
}

Submitted 7 July 2007: Accepted 16 April 2008: First published online 19 June 2008

\begin{abstract}
Objective: To assess the nutritional status of Tunisian adolescents and associated factors.

Design: A cross-sectional study based on a national stratified random cluster sample.

Subjects and methods: In all, 1295 boys and 1577 girls aged 15-19 years, of whom $28.4 \%$ had already left school. Socio-economic characteristics of the parents, anthropometric measurements, food behaviours and physical activity of the adolescents were recorded during home visits.

Results: Prevalence of underweight, overweight and obesity (WHO/National Center for Health Statistics reference) were, respectively, $8 \cdot 1 \%, 17 \cdot 4 \%$ and $4 \cdot 1 \%$ among boys and $1 \cdot 3 \%, 20 \cdot 7 \%$ and $4 \cdot 4 \%$ among girls; abdominal obesity was highly prevalent among both sexes. Prevalence of overweight differed by region (from $11 \cdot 5 \%$ to $22 \cdot 2 \%$ ) and was higher in urban $v$. rural areas for males $(21 \cdot 7 \% v$. $10 \cdot 4 \%)$ but not for females $(21 \cdot 7 \% v .19 \cdot 2 \%)$. These differences were partially mediated by socio-economic and lifestyle factors for males. For females, influence of cultural factors is hypothesised. In rural areas, overweight was more prevalent among boys of higher economic level households, having a working mother or a sedentary lifestyle; for girls, prevalence increased with the level of education of the mother. In urban areas, prevalence of overweight was related to eating habits: it was higher for boys with irregular snacking habits and for girls skipping daily meals. Urban girls having left school were also more overweight.

Conclusion: Overweight and abdominal obesity in late adolescence have become a true public health problem in Tunisia with the combined effects of cultural tradition for girls in rural areas, and of rapid economic development for boys and girls in cities.
\end{abstract}

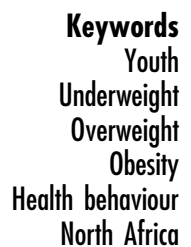

The worldwide progression of obesity ranks it now as a major public health concern in developed countries and also in many developing countries ${ }^{(1)}$. Tunisia, a middleincome developing country that has undergone significant socio-economic changes, is no exception, as more than half $(51 \%)$ of the adult women were already classified as overweight in the last nationwide survey in $1997^{(2)}$.

After a variable time lag, overweight and obesity are also significantly affecting children and adolescents, sometimes faster than adults ${ }^{(3)}$. A recent review indicates that $10 \%$ of the world's school-aged children have excess body fat; among these, $25 \%$ are obese, with a significant likelihood of some developing type 2 diabetes or heart disease during adulthood ${ }^{(4)}$. According to surveys done since 1990, the Middle Eastern Mediterranean region ranks third after the American continent and Europe for the prevalence of overweight and obesity among schoolaged children, as defined by criteria of the International Obesity Taskforce (IOTF). While specific data are scarce for North Africa ${ }^{(4)}$, various surveys conducted in the past in Tunisia or Morocco indicated a progression of obesity in pre-school children and in adults over 20 years ${ }^{(2,5,6)}$; this probably implies a progression at all ages, including school-aged children and adolescents. However, until recently more attention was paid to undernutrition, which 
is still a significant problem in many pre-school and even school-aged children in various countries ${ }^{(7-9)}$. In Tunisia, while one study showed that overweight was prevalent in an urban sample of school-aged children and adolescents $^{(10)}$, there has been no regional or national review of the extent of the problem. As in any country undergoing rapid nutrition transition, the pace and extent of changes may vary according to the region depending on the level of urbanisation and of the social and economic transformation ${ }^{(11)}$. Thus, the aim of the present study was to assess the nutritional status of 15-19-year-old adolescents and to identify associated factors at the national and regional levels, to help target preventive actions. Among these factors, we studied the association with physical activity for which there is growing evidence of its important role, and eating behaviours. While studies on energy intake are conflicting, eating behaviours (e.g. greater away from home consumption, increasing prevalence of snacking or decline in breakfast consumption) have been shown elsewhere to be associated with overweight in children or adolescents ${ }^{(12,13)}$. Also, as most studies refer only to schooled adolescents, while up to one-third drop out of school at these ages ${ }^{(14)}$, we paid specific attention to those no longer attending school.

\section{Methodology}

\section{Study area}

Tunisia is a North African country with a population of about ten million and a middle-income developing country economy (gross domestic product per capita: 8800 (purchasing power parity; US\$) in 2006). It has a long Mediterranean coastline in the north and the east. Geographical contrasts, inland on the west $v$. coastal regions in the east, as well as a marked climatic and agricultural gradient from Mediterranean in the north to desert in the south, result in pronounced economic differences between the seven administrative regions of the country (see Fig. 1). The main cities and prosperous industrial and tourist activities are concentrated along the eastern regions, with the District of Tunis (the capital) in the north east being the most developed. By contrast, the western inland parts, especially the North West and Centre West regions, often hilly or mountainous, have not reached the same level of economic and social development. Thus, in the present study, for analysis purposes the regions were grouped as coastal (North East, District of Tunis, Centre East, South East) $v$. inland (North West, Centre West, South West), the coastal group being labelled 'more developed' (MD) and the inland group 'less developed' (LD).

\section{Study design and subjects}

The target population was all Tunisian adolescents aged 15-19 years. The survey was a cross-sectional, nationally representative, stratified two-stage clustered sample of households, based on the last census of the population in 2004. It was carried out from April to September 2005. Stratification was done according to the seven administrative regions of Tunisia. Then forty-seven census districts were selected, in each region, with a probability proportional to size in number of households. At the second stage, twenty households were sampled randomly for each district selected and all the 15-19-year-olds living in the 6580 households at the time of the survey were included.

The study was approved by the Tunisian Ministry of Health and by the Home Office (Visa no. 5/2005) and was conducted by uniformly trained researchers under the direction of H.A.-S., with a supervision ensured by the regional health directions staff. Verbal consent was obtained from the adolescents and their parents before inclusion in the study. The subjects were informed of their right to refuse and of the strict respect of the confidentiality of their answers.

\section{Variables and measurement methods}

To adapt questionnaires issued from previous international studies, a translation-back-translation procedure has been followed to ensure good language accuracy and understanding.

The economic level of the household was assessed by an index constructed from correspondence analysis of the matrix of binary variables coding for type of house, number of people per room, type of drinking water supply, type of sanitation and possessions such as car, refrigerator, television, computer and satellite dish antenna ${ }^{(15,16)}$. For a given household, the coordinate on the first axis of the correspondence analysis is interpreted as a summary indicator of the economic level of the household. This index was then divided into tertiles of increasing economic level.

Information on the level of education of the parents was recoded as 'secondary or higher' $v$. others (primary or less). Their professional occupation was also assessed and recoded as 'not working' (the majority) $v$. 'working' for the mother and 'upper or intermediate', 'employee/ worker' or 'not working' (retired, unemployed) for the father. Adolescents were categorised according to whether they were registered at a school or not at the time of the survey.

Concerning eating behaviours, the subjects were asked about their usual weekly eating habits, i.e. whether they ate breakfast, lunch and dinner or a morning, afternoon or after dinner snack; 'snacks' were defined as other eating episodes apart from meals. The subjects were considered as eating daily meals if they ate all three main meals every day of the week. Regular snacking was defined as eating at least one snack daily. They were also asked about their preference for street food over home cooking as well as whether they considered that they 

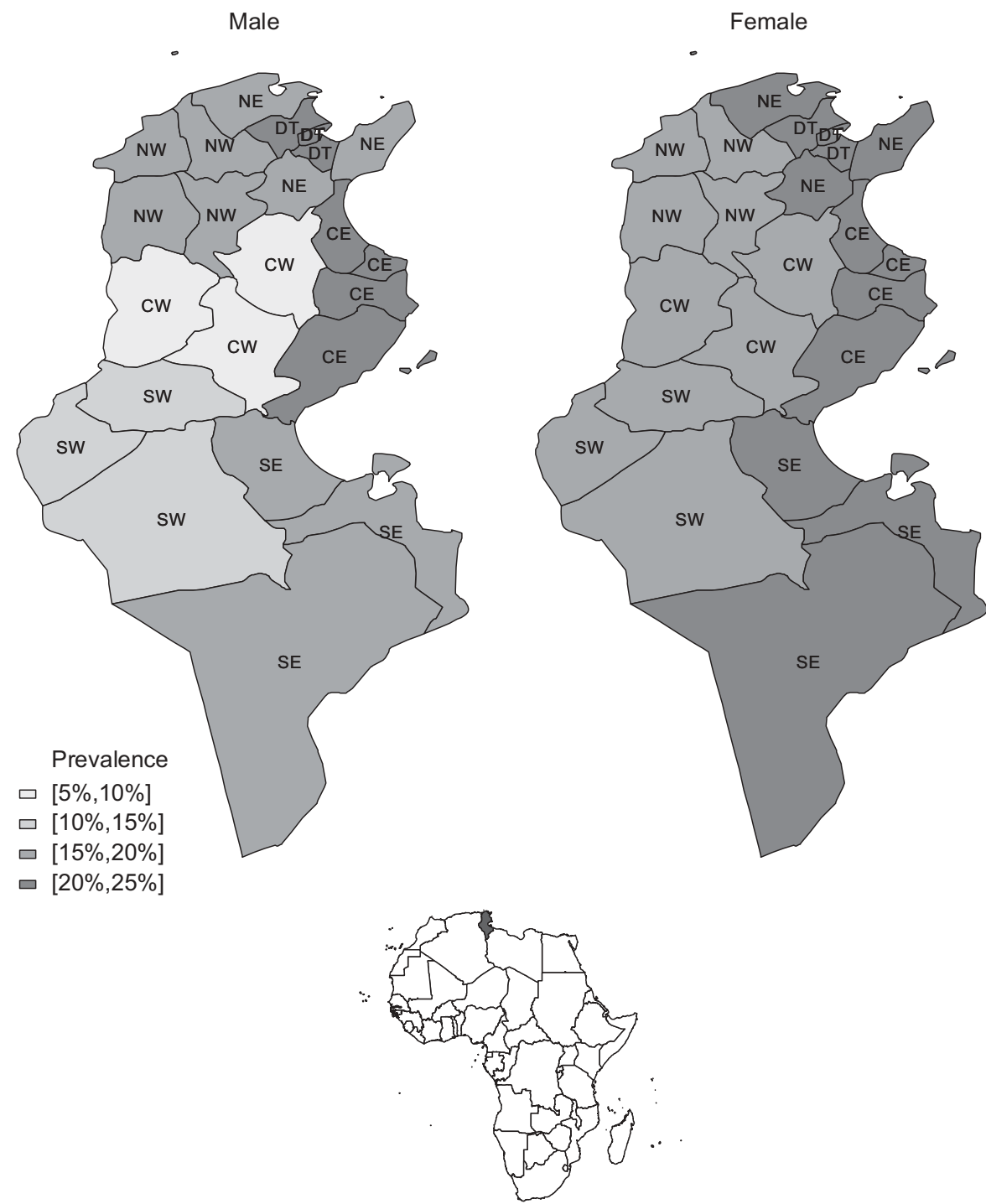

Fig. 1 Prevalence of overweight (including obesity) by region and sex (DT, District of Tunis; NW, North West region; NE, North East region; CW, Centre West region; CE, Centre East region; SW, South West region; SE, South East region)

themselves controlled their dietary intake to promote their health.

Physical activity during the month preceding the survey was assessed using a frequency questionnaire that had previously been validated for Tunisian adults ${ }^{(17)}$ and adapted for young people by adding more detailed questions about sport and leisure activities ${ }^{(18)}$. We also added an indicator of sports activities (whether the subject had done any exercise, excluding walking, at least once during the previous week). Sedentary lifestyle was assessed by time spent watching television or surfing the Internet daily. The metabolic equivalent (MET) of daily activities was calculated using an international compendium of physical activity ${ }^{(19)}$, and intensities were classified as light, moderate or vigorous (respectively, <3, 3-6 and $\geq 6 \mathrm{MET} ; 1 \mathrm{MET}=3.5 \mathrm{ml} \mathrm{O}_{2} / \mathrm{kg}$ ) using the Centers for Disease Control and Prevention/American College of
Sports Medicine classification. Low level of physical activity was defined by the subject being over the 75th percentile of the observed distribution of percentages of daily time with light physical activity.

Weight was measured to the nearest $100 \mathrm{~g}$ by trained health personnel using electronic scales that were regularly checked for accuracy and precision (Teraillon, France). Height was measured to the nearest millimetre using portable gauges (Seca, Germany), in a standing position, without shoes. Overweight and obesity were based on the age- and sex-specific BMI reference distributions of the WHO/National Center for Health Statistics (NCHS) data according to WHO recommendations ${ }^{(20)}$. Underweight was defined as BMI for age and sex $<5$ th percentile, overweight (therefore including obesity) as $\mathrm{BMI} \geq 85$ th percentile and obesity as $\mathrm{BMI} \geq 95$ th percentile. For the purpose of comparison, the IOTF definition 
for child overweight and obesity was also sometimes used $^{(21)}$. Waist circumference was measured to the nearest $0 \cdot 1 \mathrm{~cm}$ with a non-elastic metric measuring tape with subjects standing in underclothes. Abdominal obesity was defined as waist circumference $\geq 75$ th percentile of the observed distribution by age and sex.

\section{Data management and statistical analysis}

Data were entered with Epidata software, version $3 \cdot 1^{(22)}$ and were validated by double entry and standard quality check procedures.

Sampling weights were computed to account for the differential probabilities of selection in each stratum and also included a post-stratification on sex and urban $v$. rural. Comparisons of means were done through ANOVA and $\chi^{2}$ tests were used for the comparison of percentages. Associations between underweight, overweight (including obesity) or obesity and relevant factors were assessed by prevalence OR. Thus logistic regression models with underweight, overweight (including obesity) or obesity alone as the response variable were used to assess the effect of the different factors, including relevant confounders and/or interactions, and to estimate adjusted ORs. Analyses of factors associated with overweight were disaggregated by sex and area (urban/rural). The type I error risk was set at $0 \cdot 05$. Data management and analysis were performed using Stata 9 ${ }^{(23)}$, and all analyses took the sampling design into account (stratification, clustering and sampling weights).

\section{Results}

\section{Characteristics of the sample}

From the 6580 households initially selected, according to the average 0.48 ratio of $15-19$-year-olds per household (2004 Tunisian census), about 3138 subjects were to be included. Finally 2928 adolescents belonging to 2261 households were included and the final sample analysed comprised 2872 subjects (response rate: 91.5\%). The main characteristics of adolescents, after taking sampling weights into account, are presented in Table 1 . The mean age was $17 \cdot 4$ (SE 0.03) years. As expected, the proportion of urban households differed markedly between regions. About a third of the fathers had reached at least a secondary level of education, and $20 \%$ of mothers, but only $12.7 \%$ of mothers were working. The economic level of the households, as well as the level of education and occupational categories of the parents, varied significantly across regions and areas. The percentage of adolescent schooling also varied markedly between areas and between regions, the highest rate being found, as expected, in the cities, more specifically in the capital city.

\section{Nutritional status}

Overall, $4 \cdot 8 \%$ (CI $3 \cdot 8,5 \cdot 9$ ) of adolescents were underweight, males more frequently than females $(8 \cdot 1 \% \mathrm{v}$. $\left.1 \cdot 3 \%, P<10^{-4}\right)$. The prevalence of underweight was the same in urban and rural areas, but males were more underweight than females in both areas (Fig. 2), thus with no interaction between sex and area $(P=0 \cdot 61)$. There were no overall differences by groups of regions, males being however more underweight in each group (LD or MD).

Based on the WHO/NCHS reference, 19\% of adolescents were overweight (including obesity) (CI 17·2, 21·0), and $4 \cdot 3 \%(\mathrm{CI} 3 \cdot 3,5 \cdot 4)$ were obese, with no difference by sex. Based on the IOTF reference (data not shown), the overall prevalence of overweight (15\%) and obesity (2.6\%) was lower and also differed by sex, being $12.9 \%$ for males and $17 \cdot 3 \%$ for females for overweight $(P=0 \cdot 014)$, and, respectively, $1 \cdot 9 \% v \cdot 3 \cdot 2 \%$ for obesity $(P=0 \cdot 15)$.

Urban and rural areas did not differ with respect to the prevalence of obesity, but prevalence of overweight was higher in urban $v$. rural areas $(21.7 \% \quad v$. 14.7\%, $P<0 \cdot 001$ ), specifically for males (Fig. 2), but not for females (sex $\times$ area interaction $P<0 \cdot 01$ ). The effect of area on the prevalence of overweight among males was partially mediated by socio-economic factors, as the urban $v$. rural OR varied from 2.38 (CI 1.56, 3.64; $P<0 \cdot 001)$ unadjusted, to $1 \cdot 74$ (CI $1 \cdot 07,2 \cdot 83 ; P=0 \cdot 026$ ) after adjustment for socio-economic factors (schooling, education level and occupation of the parents and economic level of the household) and lifestyle (physical activity, frequency of meals and snacking). On the contrary, there were no urban $v$. rural differences for females, either before adjustment: $\mathrm{OR}=1 \cdot 16 \quad(\mathrm{CI} 0 \cdot 85,1.57$; $P=0 \cdot 34)$ or after: $\mathrm{OR}=1 \cdot 11(\mathrm{CI} 0 \cdot 75,21 \cdot 66 ; P=0 \cdot 59)$.

Prevalence of overweight differed between the seven regions from $11.5 \%$ in the Centre West to $22 \cdot 2 \%$ in the Tunis region $(P=0 \cdot 0083)$. Differences were gender specific (Fig. 1), as no effect was observed for females $(P=0.52)$, while sharp regional contrasts did appear for males (from $22.8 \%$ in the Centre East to $6.9 \%$ in the Centre West). When grouping regions according to the level of development, for males overweight was more prevalent in $\mathrm{MD} v$. LD regions $(P<0 \cdot 001)$, but only marginally so for females $(P=0.054)$. For males, the difference in prevalence of overweight between groups of regions was partly explained by socio-economic and lifestyle factors as the MD $v$. LD OR varied from 1.96 (CI $1 \cdot 31,2 \cdot 92 ; P=0 \cdot 001$ ) unadjusted, to $1 \cdot 70$ (CI $1 \cdot 08,2 \cdot 65$; $P=0 \cdot 021)$ after adjustment. These MD $v$. LD OR in the female group were, respectively, 1.33 (CI 1.00, 1.78; $P=0.054$ ) and 1.28 (CI $0.91,1.80 ; P=0.15$ ). No MD $v$. LD contrasts were observed for obesity by gender, in spite of a slight overall difference between MD and LD (4.9\% $v$. $3 \cdot 1 \% ; P=0 \cdot 046)$.

There was no difference between genders for abdominal obesity. The percentage was significantly higher in urban $v$. rural areas and was mainly due to the observed difference in the male group ( $\operatorname{sex} \times$ area interaction, 
Table 1 Socio-economic characteristics and nutritional status (sample weighted results)

\begin{tabular}{|c|c|c|c|c|c|c|c|c|}
\hline & \multirow[b]{3}{*}{$n$} & \multirow[b]{3}{*}{ National (2872) } & \multirow{2}{*}{\multicolumn{3}{|c|}{ Areas }} & \multicolumn{3}{|c|}{ Regions } \\
\hline & & & & & & \multicolumn{3}{|c|}{ Grouped by level of development } \\
\hline & & & Urban (1533) & Rural (1339) & $P$ & $\begin{array}{l}\text { More developed } \\
\quad(1509)\end{array}$ & $\begin{array}{l}\text { Less developed } \\
\quad(1363)\end{array}$ & $P$ \\
\hline \multicolumn{9}{|l|}{ Socio-economic features } \\
\hline Age (years), mean (SE) & 2872 & $17.38(0.03)$ & $17 \cdot 40(0.04)$ & $17.34(0.04)$ & 0.22 & $17.39(0.04)$ & $17.36(0.04)$ & $0 \cdot 61$ \\
\hline Male/female (\%) & 2872 & $51 \cdot 1 / 48 \cdot 9$ & $51 \cdot 0 / 49 \cdot 0$ & $51 \cdot 2 / 48 \cdot 8$ & 0.92 & $51 \cdot 0 / 49 \cdot 0$ & $51 \cdot 2 / 48 \cdot 8$ & 0.94 \\
\hline Schooling (\%) & 2866 & $71 \cdot 6$ & $79 \cdot 0$ & $59 \cdot 4$ & $<10^{-4}$ & 73.9 & $67 \cdot 2$ & 0.014 \\
\hline Urban (\%) & 2872 & $62 \cdot 3$ & - & - & - & 73.5 & $40 \cdot \overline{6}$ & $<10^{-4}$ \\
\hline $\mathrm{HH}$ economic level (\%) & 2734 & & & & & & & \\
\hline Low & 1172 & $37 \cdot 9$ & $20 \cdot 4$ & $66 \cdot 1$ & $<10^{-4}$ & $28 \cdot 5$ & $55 \cdot 7$ & $<10^{-4}$ \\
\hline Intermediate & 980 & $34 \cdot 0$ & $37 \cdot 7$ & $28 \cdot 1$ & & $34 \cdot 8$ & $32 \cdot 6$ & \\
\hline \multirow{2}{*}{\multicolumn{9}{|c|}{$\begin{array}{l}\text { Education level } \\
\text { (\% > primary school) }\end{array}$}} \\
\hline & & & & & & & & \\
\hline Father & 2842 & $32 \cdot 6$ & $42 \cdot 2$ & $16 \cdot 9$ & $<10^{-4}$ & $39 \cdot 8$ & $18 \cdot 8$ & $<10^{-4}$ \\
\hline Mother & 2844 & $20 \cdot 0$ & $27 \cdot 1$ & $8 \cdot 5$ & $<10^{-4}$ & $26 \cdot 7$ & $7 \cdot 2$ & $<10^{-4}$ \\
\hline Father's occupation (\%) & 2838 & & & & & & & \\
\hline Upper & 632 & $24 \cdot 5$ & $27 \cdot 8$ & $19 \cdot 3$ & 0.0019 & $27 \cdot 2$ & $19 \cdot 3$ & 0.0054 \\
\hline Intermediate & 1763 & $59 \cdot 9$ & $56 \cdot 1$ & $66 \cdot 0$ & & $57 \cdot 1$ & $65 \cdot 2$ & \\
\hline Not working & 443 & $15 \cdot 6$ & $16 \cdot 2$ & $14 \cdot 7$ & & $15 \cdot 7$ & $15 \cdot 5$ & \\
\hline Working mother (\%) & 2856 & $12 \cdot 7$ & $16 \cdot 7$ & $6 \cdot 1$ & $<10^{-4}$ & $16 \cdot 3$ & $5 \cdot 9$ & $<10^{-4}$ \\
\hline \multicolumn{9}{|l|}{ Nutritional status } \\
\hline \multicolumn{9}{|l|}{ Underweight (\%) } \\
\hline All & 2872 & $4 \cdot 8$ & $4 \cdot 8$ & $4 \cdot 8$ & 0.97 & $4 \cdot 6$ & $5 \cdot 2$ & 0.54 \\
\hline Male & 1295 & $8 \cdot 1$ & $8 \cdot 2$ & $7 \cdot 8$ & $0 \cdot 84$ & $7 \cdot 5$ & $9 \cdot 1$ & 0.41 \\
\hline Female & 1577 & $1 \cdot 3$ & $1 \cdot 2$ & 1.5 & 0.65 & $1 \cdot 5$ & $1 \cdot 1$ & 0.54 \\
\hline \multicolumn{9}{|l|}{ Overweight (\%) } \\
\hline All & 2872 & $19 \cdot 0$ & $21 \cdot 7$ & $14 \cdot 7$ & $<10^{-3}$ & $21 \cdot 3$ & $14 \cdot 6$ & $<10^{-3}$ \\
\hline Male & 1295 & $17 \cdot 4$ & $21 \cdot 7$ & $10 \cdot 4$ & $<10^{-3}$ & $20 \cdot 4$ & $11 \cdot 6$ & $<10^{-3}$ \\
\hline Female & 1577 & $20 \cdot 7$ & $21 \cdot 7$ & $19 \cdot 2$ & 0.34 & $22 \cdot 3$ & $17 \cdot 7$ & 0.054 \\
\hline \multicolumn{9}{|l|}{ Obesity (\%) } \\
\hline All & 2872 & $4 \cdot 3$ & $4 \cdot 7$ & 3.5 & $0 \cdot 19$ & $4 \cdot 9$ & $3 \cdot 1$ & 0.046 \\
\hline Male & 1295 & $4 \cdot 1$ & $4 \cdot 8$ & $2 \cdot 8$ & $0 \cdot 15$ & $4 \cdot 6$ & $3 \cdot 1$ & 0.25 \\
\hline Female & 1577 & $4 \cdot 4$ & $4 \cdot 6$ & $4 \cdot 2$ & $0 \cdot 78$ & $5 \cdot 1$ & $3 \cdot 1$ & $0 \cdot 10$ \\
\hline \multicolumn{9}{|l|}{ Abdominal obesity (\%) } \\
\hline All & 2860 & $28 \cdot 0$ & $30 \cdot 9$ & $23 \cdot 2$ & 0.0020 & $33 \cdot 0$ & $18 \cdot 2$ & $<10^{-4}$ \\
\hline Male & 1288 & $28 \cdot 4$ & 33.9 & $19 \cdot 4$ & $<10^{-4}$ & $34 \cdot 2$ & $17 \cdot 2$ & $<10^{-4}$ \\
\hline Female & 1572 & $27 \cdot 6$ & $27 \cdot 9$ & $27 \cdot 2$ & 0.82 & $31 \cdot \overline{9}$ & $19 \cdot 2$ & $<10^{-4}$ \\
\hline
\end{tabular}




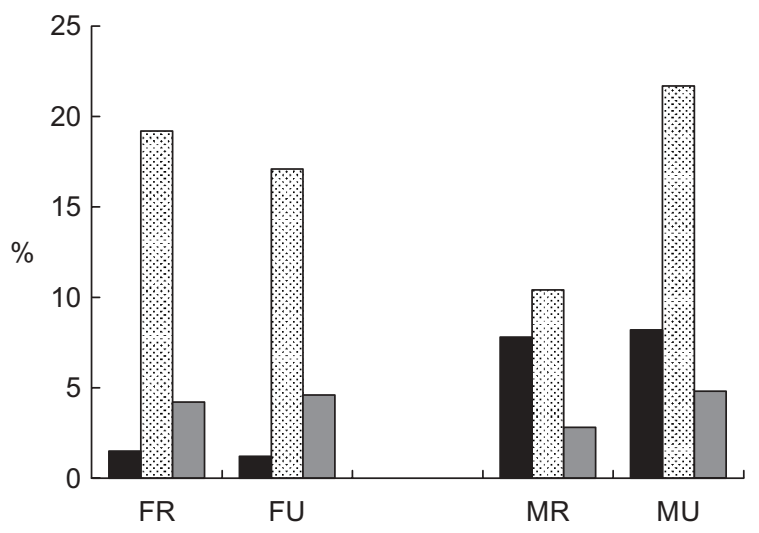

Fig. 2 Prevalence of underweight $(\square)$, overweight including obesity ( $\square$ ) and obesity ( $\square$ ) by area and sex. For underweight: MR v. FR, $P<10^{-4}$; MU v. FU, $P<10^{-4}$. For overweight: MU v. MR, $P<10^{-3}$; MR v. FR, $P<10^{-3}$ (MR, male-rural; FR, female-rural; MU, male-urban; FU, female-urban)

$P<0 \cdot 001$ ). For males, the urban $v$. rural OR decreased after adjustment for socio-economic and lifestyle factors from $2 \cdot 14$ (CI $1 \cdot 52,3 \cdot 00 ; P<10^{-4}$ ) to $1 \cdot 46$ (CI $0 \cdot 98,2 \cdot 18$; $P=0 \cdot 063$ ), but not for females, from $1 \cdot 03$ (CI $0 \cdot 78,1 \cdot 37$; $P=0 \cdot 82)$ to $1 \cdot 14($ CI $0 \cdot 79,1 \cdot 64 ; P=0 \cdot 49)$. Prevalence of abdominal obesity was different between the two groups of regions, with no significant interaction between sex and region $(P=0 \cdot 23)$. The difference between regions (MD $v$. LD) was not mediated by family socio-economic and lifestyle factors as OR varied for males, from $2 \cdot 49$ (CI 1.79, 3.45; $P<0 \cdot 001$ ) unadjusted, to $2 \cdot 40$ (CI 1.65 , 3.49; $P<0 \cdot 001)$ after adjustment, and for females, it varied from 1.97 (CI $1 \cdot 49,2 \cdot 60 ; P<0 \cdot 0001$ ) to $2 \cdot 22$ (CI $1 \cdot 60$, 3.08; $P<0 \cdot 001)$.

\section{Eating bebaviour and physical activity}

Skipping meals was frequent (29.5\%), especially among females (Table 2). Breakfast and dinner were the most frequently skipped. No difference was observed between areas either for males or for females. Around $40 \%$ of adolescents snacked regularly between meals; snacking in the afternoon and after dinner was significantly higher in urban areas for both sexes, but more frequent for males than for females. The percentage of adolescents who declared they preferred street food was $17 \%$ with no difference between sexes. This proportion was higher in urban areas for both sexes. Regional differences were observed, but only for females (higher proportion in the MD group of regions). Almost half of the adolescents, and slightly more females than males, declared that they controlled their dietary behaviour. The prevalence of sport was significantly higher for males, as could be expected. It was slightly higher in urban $v$. rural areas $(71 \cdot 1 \%$ v. $65 \cdot 4 \%, P=0 \cdot 028)$, the difference being significant only in the female group. Sedentary behaviour was general and significantly more prevalent among females. The mean duration of watching television or surfing the Internet was higher for females $(95 \cdot 2$ (SE 3.4) v. $87 \cdot 0(\operatorname{se~} 3 \cdot 6) \mathrm{min} / \mathrm{d})$ and was generally higher in urban $v$. rural areas and in the MD $v$. LD group of regions, with a significant difference found mainly for females. The proportion of adolescents who reported a low level of physical activity was significantly higher for females independently of the area or region.

\section{Adolescents not attending school}

Among the $28.4 \%$ of adolescents not attending school, $40 \cdot 8 \%$ (of whom $65 \cdot 8 \%$ were male and $34 \cdot 2 \%$ female) had a salaried job while the others stayed at home. Among those not attending school, for both sexes the economic level of the household was higher $(P<0 \cdot 001)$ for the 'salaried' $v$. the 'stay at home' group (data not shown). Salaried adolescents were more frequent in urban $v$. rural areas $\left(53.0 \%\right.$ v. $\left.30 \cdot 4 \%, P<10^{-4}\right)$. Prevalence of overweight was $19.9 \%$ in adolescents not attending school, similar to the prevalence in the overall sample (19.1\%), but was higher for salaried adolescents $v$. those staying at home (respectively, $23 \cdot 8 \%$ and $16 \cdot 7 \%$, $P=0 \cdot 048)$. By sex, the salaried males were more overweight than those staying at home (18.8\% v. 9.4\%, $P=0 \cdot 022$ ), but less significantly so for females (respectively, $35 \cdot 0 \%$ v. $23 \cdot 0 \%, P=0 \cdot 073$ ).

\section{Factors associated with overweight}

As factors associated with overweight differed for males $v$. females as well as for urban $v$. rural areas, separate analyses are presented. For males in urban areas (Table 3), overweight was associated with irregular snacking habits (OR $=1 \cdot 76, P=0 \cdot 016)$ and marginally significantly so with skipping daily meals $(\mathrm{OR}=1.5, P=0.077)$. For males in rural areas, overweight was associated with the mother working outside the home $(\mathrm{OR}=4 \cdot 9, P<0 \cdot 001)$ and low physical activity $(\mathrm{OR}=2 \cdot 7, P=0 \cdot 009)$. Overweight also increased with socio-economic level of the household $(\mathrm{OR}=3.8$ and 2.5 , respectively, for high and intermediate $v$. low, $P=0 \cdot 055)$. For females in urban areas (Table 4), overweight was associated with not attending school $(\mathrm{OR}=2.9, \quad P<0.001)$ and skipping daily meals $(\mathrm{OR}=1 \cdot 6, P=0 \cdot 047)$. For females in rural areas, the only association found was with level of education of the mother (primary or less $v$. other, $\mathrm{OR}=2 \cdot 4$, $P=0 \cdot 026)$.

\section{Discussion}

Our study aimed at updating the prevalence and factors associated with nutritional status of Tunisian adolescents. Associations should of course not be interpreted further than the cross-sectional design permits. Also, the study does not feature direct assessment of dietary intake, although in many cases it has been difficult to relate it to 
Table 2 Factors related to food behaviour and physical activity by sex, area or region

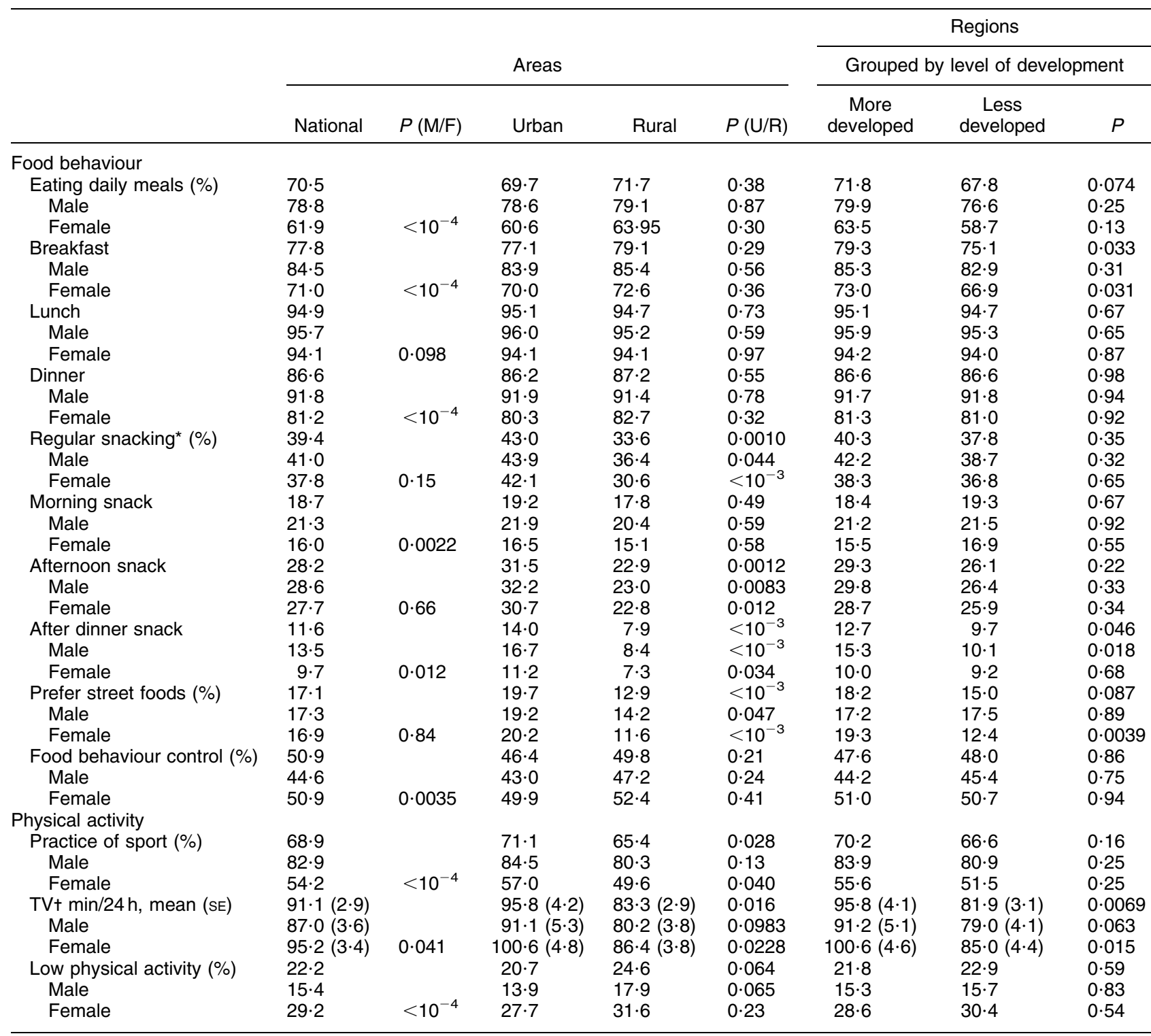

$M$, male; $F$, female; $U$, urban; $R$, rural.

${ }^{*}$ At least once daily.

tWatching television and/or Internet.

overweight in adolescents contrary to food-related behaviours $^{(12)}$, which our study does assess.

\section{Nutritional status}

With reference to a national nutrition survey conducted in 1996-97 ${ }^{(24)}$, which gave limited data for the 15-19-year age class, in 2005 underweight had decreased from $14 \cdot 4 \%$ to $8 \cdot 1 \%$ for males and from $3 \cdot 3 \%$ to $1 \cdot 3 \%$ for females. During the same period overweight had increased markedly from $2.9 \%$ to $17 \cdot 4 \%$ for males and from $13.5 \%$ to $20 \cdot 7 \%$ for females. A similar trend has been observed in developing countries which underwent a rapid socio-economic transition ${ }^{(8)}$ as did Tunisia, whose Human Development Index rose from 0.515/1.0 in 1975 to $0 \cdot 765 / 1 \cdot 0$ in $2005^{(25)}$. Thus, the overall prevalence of overweight in adolescents aged 15-19 years is currently high in Tunisia. However, it is still lower than in other Arab countries with prevalence in this age class being around or over $30 \%{ }^{(26-28)}$. Rather, the situation is similar to that of most European countries, where the prevalence of overweight ranges from $20 \%$ to $12 \%{ }^{(29,30)}$. Analogous results for overweight were also observed recently in a city from eastern $\operatorname{Algeria}^{(31)}$, indicating that this rapid increase in prevalence may concern other North African countries as well, in spite of the lack of nationally representative data. Moreover, our study shows that the increase is not limited to BMI, but also affects waist circumference, an overall marker for higher risks to develop 
Table 3 Correlates of overweight (including obesity): males

\begin{tabular}{|c|c|c|c|c|c|c|c|c|c|c|c|c|c|c|c|c|}
\hline & \multicolumn{8}{|c|}{ Urban } & \multicolumn{8}{|c|}{ Rural } \\
\hline & \multirow[b]{2}{*}{$n$} & \multirow[b]{2}{*}{ OW (\%) } & \multicolumn{3}{|c|}{ Unadjusted OR } & \multicolumn{3}{|c|}{ Adjusted OR* } & \multirow[b]{2}{*}{$n$} & \multirow[b]{2}{*}{ OW (\%) } & \multicolumn{3}{|c|}{ Unadjusted OR } & \multicolumn{3}{|c|}{ Adjusted OR* } \\
\hline & & & OR & $\mathrm{Cl}$ & $P$ & OR & $\mathrm{Cl}$ & $P$ & & & OR & $\mathrm{Cl}$ & $P$ & OR & $\mathrm{Cl}$ & $P$ \\
\hline \multicolumn{17}{|l|}{ Schooling } \\
\hline Yes & 543 & $22 \cdot 2$ & $1 \cdot 00$ & - & \multirow{2}{*}{$0 \cdot 61$} & 1.00 & - & \multirow[t]{2}{*}{$0 \cdot 60$} & 351 & $11 \cdot 5$ & 1.00 & - & \multirow[t]{2}{*}{0.35} & 1.00 & - & \multirow{2}{*}{$0 \cdot 84$} \\
\hline No & 162 & $20 \cdot 0$ & 0.87 & $0.52,1.48$ & & 0.84 & $0.44,1.61$ & & 237 & $8 \cdot 8$ & 0.74 & $0.40,1 \cdot 38$ & & 0.93 & $0.44,1.95$ & \\
\hline \multicolumn{17}{|c|}{ Economic level of household } \\
\hline Low & 156 & $15 \cdot 3$ & $1 \cdot 00$ & - & \multirow{3}{*}{$0 \cdot 22$} & 1.00 & - & \multirow[t]{3}{*}{$0 \cdot 18$} & 371 & $7 \cdot 8$ & 1.00 & - & \multirow[t]{3}{*}{0.060} & $1 \cdot 00$ & - & \multirow[t]{3}{*}{0.055} \\
\hline Intermediate & 261 & $21 \cdot 8$ & 1.54 & $0 \cdot 74,3 \cdot 23$ & & 1.98 & $0.85,4.59$ & & 166 & $15 \cdot 2$ & $2 \cdot 13$ & $1 \cdot 02,4.45$ & & $2 \cdot 51$ & $1 \cdot 09,5 \cdot 80$ & \\
\hline High & 252 & $24 \cdot 4$ & $1 \cdot 79$ & $0.92,3.48$ & & $2 \cdot 16$ & $0.95,4.91$ & & 31 & $18 \cdot 1$ & $2 \cdot 62$ & $0 \cdot 88,7 \cdot 76$ & & $3 \cdot 75$ & $0 \cdot 74,18.98$ & \\
\hline \multicolumn{17}{|c|}{ Father's occupational category } \\
\hline Upper & 180 & $25 \cdot 8$ & $1 \cdot 00$ & - & \multirow{3}{*}{$0 \cdot 37$} & 1.00 & - & \multirow{3}{*}{$0 \cdot 46$} & 106 & $7 \cdot 6$ & $1 \cdot 00$ & - & \multirow[t]{3}{*}{0.65} & $1 \cdot 00$ & - & \multirow[t]{3}{*}{0.64} \\
\hline Intermediate & 398 & $20 \cdot 7$ & $0 \cdot 75$ & $0 \cdot 45,1 \cdot 26$ & & 0.90 & $0 \cdot 46,1 \cdot 75$ & & 380 & $10 \cdot 5$ & $1 \cdot 43$ & $0.64,3.23$ & & $1 \cdot 48$ & $0 \cdot 65,3 \cdot 36$ & \\
\hline Not working & 119 & $17 \cdot 8$ & 0.62 & $0 \cdot 31,1 \cdot 26$ & & 0.61 & $0 \cdot 28,1 \cdot 37$ & & 98 & $11 \cdot 0$ & 1.51 & $0.55,4 \cdot 16$ & & $1 \cdot 35$ & $0 \cdot 49,3 \cdot 73$ & \\
\hline Mother's occupational c & & & & & & & & & & & & & & & & \\
\hline Not working & 603 & $21 \cdot 0$ & $1 \cdot 00$ & - & 0.33 & $1 \cdot 00$ & - & 0.55 & 554 & $9 \cdot 0$ & $1 \cdot 00$ & - & $<10^{-3}$ & $1 \cdot 00$ & - & $<10^{-3}$ \\
\hline Working & 101 & $25 \cdot 4$ & $1 \cdot 28$ & $0 \cdot 77,2 \cdot 13$ & & $0 \cdot 82$ & $0.42,1.59$ & & 33 & $31 \cdot 9$ & $4 \cdot 74$ & $2 \cdot 23,10 \cdot 06$ & & $4 \cdot 88$ & $2 \cdot 14,11 \cdot 14$ & \\
\hline Father's education level & & & & & & & & & & & & & & & & \\
\hline Primary or less & 422 & $20 \cdot 8$ & $1 \cdot 00$ & _- & $0 \cdot 61$ & $1 \cdot 00$ & - & 0.34 & 502 & $10 \cdot 6$ & $1 \cdot 00$ & _- & 0.75 & $1 \cdot 00$ & - & 0.29 \\
\hline Secondary or higher & 271 & $22 \cdot 5$ & $1 \cdot 11$ & $0 \cdot 75,1 \cdot 63$ & & 0.78 & $0.46,1 \cdot 31$ & & 84 & $9 \cdot 5$ & $0 \cdot 88$ & $0.40,1.95$ & & 0.53 & $0.17-1.71$ & \\
\hline Mother's education leve & & & & & & & & & & & & & & & & \\
\hline Primary or less & 522 & $19 \cdot 4$ & $1 \cdot 00$ & - & 0.088 & 1.00 & - & 0.29 & 540 & $10 \cdot 4$ & $1 \cdot 00$ & - & 0.90 & $1 \cdot 00$ & - & 0.68 \\
\hline Secondary or higher & 172 & $26 \cdot 4$ & $1 \cdot 50$ & $0.94,2 \cdot 38$ & & $1 \cdot 41$ & $0 \cdot 75,2 \cdot 64$ & & 46 & $11 \cdot 0$ & 1.06 & $0 \cdot 42,2 \cdot 67$ & & $0 \cdot 72$ & $0 \cdot 17,3 \cdot 16$ & \\
\hline Eating daily meals & & & & & & & & & & & & & & & & \\
\hline Yes & 551 & $20 \cdot 6$ & $1 \cdot 00$ & - & 0.088 & 1.00 & - & 0.077 & 463 & $9 \cdot 0$ & 1.00 & - & 0.073 & $1 \cdot 00$ & - & $0 \cdot 16$ \\
\hline No & 147 & $27 \cdot 2$ & $1 \cdot 44$ & $0 \cdot 95,2 \cdot 20$ & & 1.50 & $0 \cdot 96,2 \cdot 36$ & & 125 & $15 \cdot 9$ & 1.92 & $0.94,3.90$ & & 1.67 & $0.81,3.46$ & \\
\hline Regular snackingt & & & & & & & & & & & & & & & & \\
\hline Yes & 291 & $17 \cdot 2$ & $1 \cdot 00$ & - & 0.035 & $1 \cdot 00$ & - & 0.016 & 209 & $9 \cdot 3$ & $1 \cdot 00$ & - & 0.49 & $1 \cdot 00$ & - & $0 \cdot 10$ \\
\hline No & 388 & $24 \cdot 6$ & 1.57 & $1 \cdot 03,2 \cdot 39$ & & $1 \cdot 76$ & $1 \cdot 11,2 \cdot 80$ & & 369 & $11 \cdot 3$ & 1.25 & $0 \cdot 67,2 \cdot 35$ & & $1 \cdot 89$ & $0.88,4.06$ & \\
\hline Low physical activity & & & & & & & & & & & & & & & & \\
\hline No & 601 & $21 \cdot 7$ & $1 \cdot 00$ & - & 0.98 & 1.00 & - & $0 \cdot 60$ & 477 & $8 \cdot 7$ & 1.00 & - & 0.005 & $1 \cdot 00$ & - & 0.009 \\
\hline Yes & 106 & $21 \cdot 8$ & 1.01 & $0.59,1.73$ & & 0.84 & $0.43,1.64$ & & 111 & $18 \cdot 2$ & $2 \cdot 33$ & $1 \cdot 29,4 \cdot 23$ & & $2 \cdot 68$ & $1 \cdot 29,5 \cdot 56$ & \\
\hline
\end{tabular}

OW, overweight (including obesity).

tSnacking at least once daily. 
Table 4 Correlates of overweight (including obesity): females

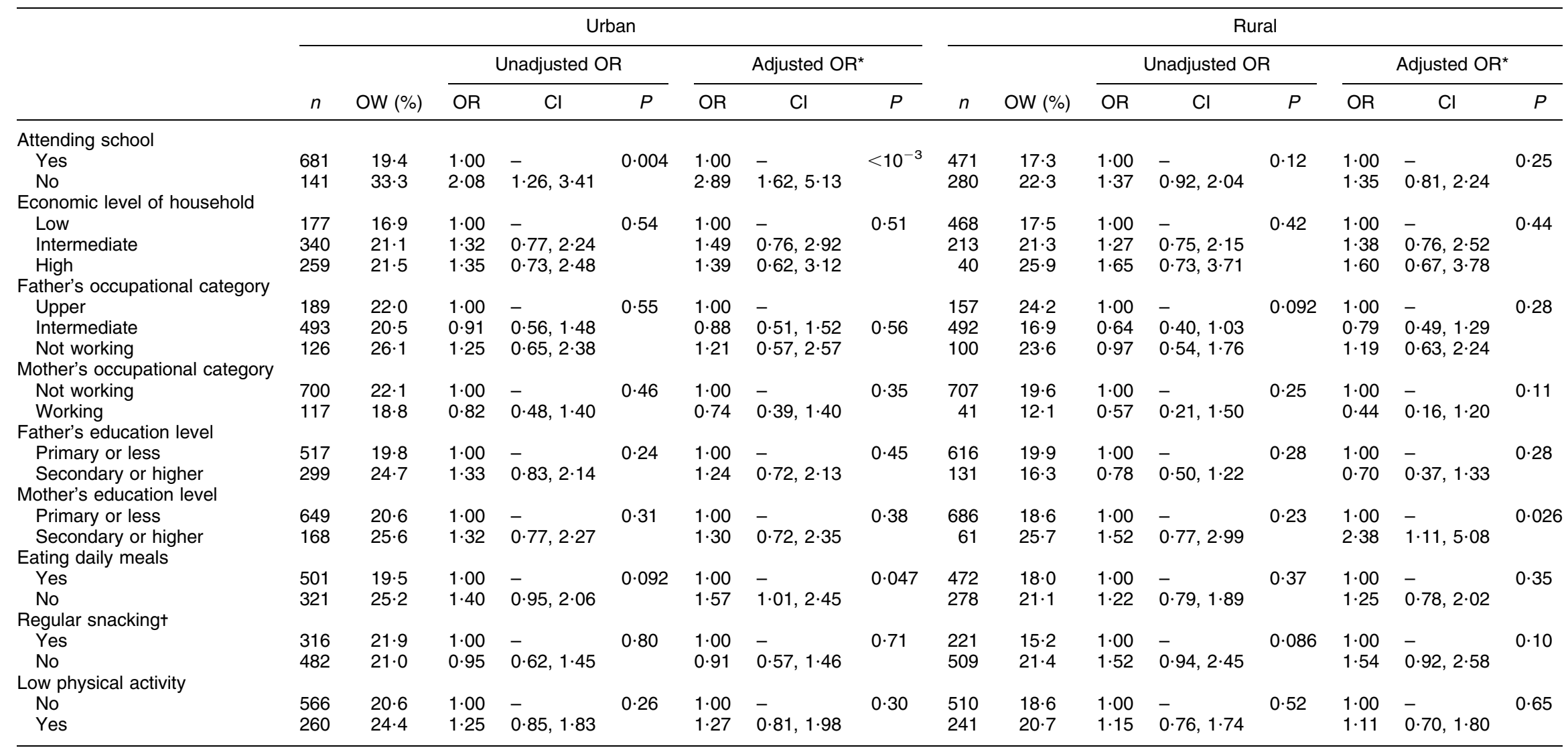

OW, overweight (including obesity).

${ }^{*}$ Adjusted for age.

+Snacking at least once daily. 
later chronic diseases. This confirms an observation made in the coastal city of Sousse, which showed a clustering of cardiovascular risk factors among obese urban schoolchildren $^{(10)}$

\section{Influence of living area}

Surprisingly, no straightforward differences were observed for the prevalence of underweight between groups of regions according to the level of development, nor between urban and rural areas. A more detailed analysis revealed though that underweight was observed predominantly in the richest (District of Tunis) and in the poorest (Centre West) of the seven administrative regions. The regular rural exodus of rather poor families towards the capital, and also the context of intra-urban economic inequalities ${ }^{(32)}$, may explain this unexpected situation.

On the contrary, for overweight, there were sharp contrasts between regions according to their level of development, and also between rural and urban areas, only for males though, in both cases. Indeed, one of the most significant results was the strong differential effect of sex on regional or urban $v$. rural differences regarding overweight: urban boys and girls appeared to be equally overweight and abdominal obesity prone, but in rural areas boys appeared to be relatively protected. For females, for which no urban $v$. rural difference was observed, whether or not taking into account socio-economic and lifestyle factors, possible inverse confounding effect of marital status on overweight ${ }^{(33)}$ was not assessed in our study because of the rarity of marriage now in this age bracket in Tunisia (around 12\%o). For males, adjusted analyses indicated that the differences observed were partly mediated by socio-economic and lifestyle factors. But the residual associations also showed that these differences might be linked to other factors, and this was further emphasised by the large difference in abdominal obesity between regions or areas that had no link with any of the socio-economic or lifestyle factors measured here. Such differences between regions ${ }^{(28,33)}$ and higher prevalence in urban $v$. rural areas ${ }^{(8,34-36)}$ are frequently reported as a consequence of a different level of exposure to genetic influences ${ }^{(37)}$ and particularly to environmental factors $^{(38)}$, and also to traditions, psychological and cultural factors that influence eating behaviours ${ }^{(38-40)}$. The higher prevalence of overweight and obesity in females $v$. males observed here in rural areas has been reported for other African countries ${ }^{(30)}$, and may also be partly linked to cultural factors. Indeed, a positive perception of overweight is often reported in Arab countries, especially for females, as it is considered to be a sign of high social status, beauty, fertility and prosperity ${ }^{(26)}$. Although the dominant model in Western countries of a thin body may gain new consideration in countries of the Mediterranean region $^{(7,27)}$, women in Mauritania, for instance ${ }^{(41)}$, or more recently Moroccan Sahraoui women ${ }^{(42,43)}$, have been shown to still value body weight and to undergo social pressure in order to maintain their overweight. With respect to our results, why would these factors result in gender-specific urban $v$. rural differences? It could be that in the urban area, the more obesity-prone socioeconomic context is somewhat counterbalanced by the Western model of a thin body.

\section{Gender/area-specific factors of nutritional status}

In rural settings, for boys, overweight was associated with increased economic level of the household, with a less available working mother and sedentariness, a classic pattern described by Sobal and Stunkard in $1989^{(44)}$. For rural girls, no direct association with the economic level of the household was observed, but only with a high level of education of the mother (which is also somewhat indicative of a higher socio-economic level, though it concerns a relative minority of mothers, as less than $9 \%$ of mothers had reached the secondary level). Nutrition transition is generally fuelled by urbanisation so that urban/rural disparities are the rule in the first phase, while the phenomenon evolves at a different pace in different parts of the country, and obesity is usually associated with a better economic status $^{(45,46)}$. A difference in prevalence of overweight between rural and urban areas as observed here for boys as well as the observed association with socioeconomic factors in rural areas fit well with this view of a first stage of the nutrition transition. It is less clear however as to why overweight is no longer associated with the socio-economic level in urban areas. It may mean that cities would be entering another step of the transition phenomenon where overweight spreads from higher to lower socio-economic layers of the society ${ }^{(45)}$.

In rural boys, low physical activity is less frequent than in girls and it appears as an important factor for overweight. A likely explanation would be a close adjustment of energy intake to energy needs of active rural boys so that any reduction in intake would lead to underweight while any reduction in activity would lead to overweight. This is not the case for rural girls as they expend generally less activity than boys and may therefore meet more easily their energy needs but are also prone to becoming more often overweight. In urban settings, regulation of energy expenditure may less be an issue, and for both sexes overweight was no longer associated with physical activity but mainly associated with eating behaviours. Although correlates of overweight may vary largely across studies, a greater number of eating episodes each day for a given total intake, and their regularity, has been classically related to a lower risk of obesity in adolescents and in adults ${ }^{(12)}$. Finally, while overweight prevalence was similar overall whether or not adolescents were attending school at these ages, a higher risk of overweight was observed in urban girls who had left school, after adjustment for all other factors. It may be related to the higher personal economic status linked with a salaried job, though this has been partly taken into account here 
(as analyses are adjusted for whether or not the subject is attending school). Alternatively, when they abandon school, girls are likely to undergo sudden changes in food and physical activity practices; although a minority, they certainly are a group at risk, which should be studied further.

\section{Conclusion}

The present study showed an overall persistence of underweight, especially for males, and a sizeable prevalence of overweight for females in rural or less economically developed regions and for both genders in urban parts. Differential factors of overweight may suggest that rural $v$. urban areas are at different stages of nutrition transition. But overall, there are serious reasons to consider overweight in adolescents as a true public health problem in Tunisia, particularly as abdominal obesity appears as a significant feature in most overweight adolescents. Educational programmes to reduce sedentary behaviour and to encourage control of dietary behaviours can be promoted in schools; however, ways should also be found to address the sizeable minority of adolescents who no longer attend school, notably working girls who appeared to be at particular risk of overweight.

\section{Acknowledgements}

Sources of funding: This study was supported by the European Commission as part of the 'Tahina' project (Epidemiological transition and its health impact in North Africa, Inco-Med Contract ICA3-CT-2002-10011) and by UNICEF.

Conflicts of interest: None to declare.

Authorship responsibilities: H.A.-S. was responsible for writing the manuscript, supervised the data collection, performed the data analysis and designed the study. P.T. and S.E.-D. contributed to data management and statistical analysis and revision of the manuscript. F.D. and N.A. contributed to the study design and revision of the manuscript. H.B.R. and B.M. participated in all steps, from the design of the study to the revision of the manuscript.

Acknowledgements: The help of the personnel of the Regional Health Directions, of the National Public Health Institute and of the National Institute of Nutrition in the data collection was greatly appreciated.

\section{References}

1. Haslam DW \& James WP (2005) Obesity. Lancet 366, 1197-1209.

2. Mokhtar N, Elati J, Chabir R, Bour A, Elkari K, Schlossman NP, Caballero B \& Agnenaou H (2001) Diet culture and obesity in northern Africa. J Nutr 131, 887S-892S.
3. Popkin BM, Conde W, Hou N \& Monteiro C (2006) Is there a lag globally in overweight trends for children compared with adults? Obesity 14, 1846-1853.

4. Lobstein T, Baur L \& Uauy R (2004) Obesity in children and young people: a crisis in public health. Obes Rev 5, Suppl. 1, S4-S104.

5. Benjelloun S (2002) Nutrition transition in Morocco. Public Health Nutr 5, 135-140.

6. Rguibi M \& Belahsen R (2007) Prevalence of obesity in Morocco. Obesity Rev 8, 11-13.

7. Bener A (2006) Prevalence of obesity, overweight, and underweight in Qatari adolescents. Food Nutr Bull 27, 39-45.

8. Wang Y, Monteiro C \& Popkin BM (2002) Trends of obesity and underweight in older children and adolescents in the United States, Brazil, China, and Russia. Am J Clin Nutr $\mathbf{7 5}$, 971-977.

9. Florencio TM, Ferreira HS, de Franca AP, Cavalcante JC \& Sawaya AL (2001) Obesity and undernutrition in a verylow-income population in the city of Maceio, northeastern Brazil. Br J Nutr 86, 277-284.

10. Ghannem H, Harrabi I, Ben Abdelaziz A, Gaha R \& Mrizak N (2003) Clustering of cardiovascular risk factors among obese urban schoolchildren in Sousse, Tunisia. East Mediterr Health J 9, 70-77.

11. Monteiro CA, Conde WL \& Popkin BM (2001) Independent effects of income and education on the risk of obesity in the Brazilian adult population. $J$ Nutr 131, 881S-886S.

12. Rodriguez G \& Moreno LA (2006) Is dietary intake able to explain differences in body fatness in children and adolescents? Nutr Metab Cardiovasc Dis 16, 294-301.

13. Newby PK (2007) Are dietary intakes and eating behaviors related to childhood obesity? A comprehensive review of the evidence. J Law Med Ethics 35, 35-60.

14. United Nations Development Programme (2003) Jeunes de Tunisie. Tunis: Bureau of the UNDP Resident Coordinator.

15. Delpeuch F, Cornu A, Massamba JP, Traissac P \& Maire B (1994) Is body mass index sensitively related to socio-economic status and to economic adjustment? A case study from the Congo. Eur J Clin Nutr 48, Suppl. 3, S141-S147.

16. Mejean C, Traissac P, Eymard-Duvernay S, El Ati J, Delpeuch F \& Maire B (2007) Influence of socio-economic and lifestyle factors on overweight and nutrition-related diseases among Tunisian migrants versus non-migrant Tunisians and French. BMC Public Health 7, 265.

17. El Ati J, Houti L, Farhat A, NguyenThan V, EymardDuvernay S, Béji C, Kolsteren P, Saada C, Gaigi S \& Maire B (2004) Development, reproducibility and validity of a physical activity frequency questionnaire in North Africa. Arab J Food Nutr 5, 148-167.

18. Nolin B, Prud'homme D, Godin G \& Hamel D (2002) Enquête québéquoise sur l'activité physique et la santé 1998. Québec: Institut de la Statistique du Québec, Institut National de Santé Publique du Québec et KinoQuébec.

19. Ainsworth BE, Haskell WL, Whitt MC et al. (2000) Compendium of physical activities: an update of activity codes and MET intensities. Med Sci Sports Exerc 32, Suppl. 9, S498-S504.

20. World Health Organization (1995) Physical Status: the Use and Interpretation of Anthropometry: Report of a WHO Expert Committee. WHO Technical Report Series no. 854. Geneva: WHO.

21. Cole TJ, Bellizzi MC, Flegal KM \& Dietz WH (2000) Establishing a standard definition for child overweight and obesity worldwide: international survey. $\mathrm{Br}$ Med J 320, 1240-1243.

22. Lauritsen J \& Bruus M (2003-2004) EpiData (version 3). A comprebensive tool for validated entry and documentation of data. Odense, Denmark: The EpiData Association. 
23. StataCorp (2005) Stata Statistical Software: Release 9. College Station, TX: StataCorp LP.

24. Institut National de la Nutrition et de la Technologie Alimentaire (1998) Evaluation de l'état nutritionnel de la population tunisienne 1996-97. Rapport National. Tunis: INNTA.

25. United Nations Development Programme (2006) Beyond Scarcity: Power, Poverty and the Global Water Crisis. Human Development Report 2006. New York: United Nations.

26. Malik M \& Bakir A (2007) Prevalence of overweight and obesity among children in the United Arab Emirates. Obes Rev 8, 15-20.

27. Sibai AM, Hwalla N, Adra N \& Rahal B (2003) Prevalence and covariates of obesity in Lebanon: findings from the first epidemiological study. Obes Res 11, 1353-1361.

28. El-Hazmi MA \& Warsy AS (2002) A comparative study of prevalence of overweight and obesity in children in different provinces of Saudi Arabia. J Trop Pediat 48, $172-177$.

29. Janssen I, Katzmarzyk PT, Boyce WF, Vereecken C, Mulvihill C, Roberts C, Currie C \& Pickett W, The Health Behaviour in School-Aged Children Obesity Working Group (2005) Comparison of overweight and obesity prevalence in school-aged youth from 34 countries and their relationships with physical activity and dietary patterns. Obes Rev 6, 123-132.

30. York DA, Rossner S, Caterson I, Chen CM, James WPT, Kumanyika S, Martorell R \& Vorster HH (2004) Prevention Conference VII: Obesity, a worldwide epidemic related to heart disease and stroke. Group I: worldwide demographics of obesity. Circulation 110, e463-470.

31. Mekhancha-Dahel CC, Mekhancha DE, Bahchachi N, Benatallah L \& Nezzal L (2005) Overweight, obesity: signs of nutritional transition in children and adolescents in Khroub, Algeria. Rev Epidemiol Sante Publique 53, 569-573.

32. United Nations Development Programme (2004) Poverty Reduction Strategies. A Study of Poverty in Tunisia. Tunis: Bureau of the UNDP Resident Coordinator.

33. Erem C, Arslan C, Hacihasanoglu A, Deger O, Topbas M, Ukinc K, Ersöz HO \& Telatar M (2004) Prevalence of obesity and associated risk factors in a Turkish population (Trabzon city, Turkey). Obes Res 12, 1117-1127.

34. Yamamoto-Kimura L, Posadas-Romero C, Posadas-Sanchez R, Zamora-Gonzalez J, Cardoso-Saldana G \& Mendez Ramirez I
(2006) Prevalence and interrelations of cardiovascular risk factors in urban and rural Mexican adolescents. $J$ Adolesc Health 38, 591-598.

35. Salazar-Martinez E, Allen B, Fernandez-Ortega C, TorresMejia G, Galal O \& Lazcano-Ponce E (2006) Overweight and obesity status among adolescents from Mexico and Egypt. Arch Med Res 37, 535-542.

36. Kelishadi R, Pour MH, Sarraf-Zadegan N, Sadry GH, Ansari R, Alikhassy H \& Bashardoust N (2003) Obesity and associated modifiable environmental factors in Iranian adolescents: Isfahan Healthy Heart Program Heart Health Promotion from Childhood. Pediatr Int 45, 435-442.

37. Martinez JA (2000) Obesity in young Europeans: genetic and environmental influences. Eur J Clin Nutr 54, Suppl. 1, S56-S60.

38. van der Horst K, Oenema A, Ferreira I, Wendel-Vos W, Giskes K, van Lenthe F \& Brug J (2007) A systematic review of environmental correlates of obesityrelated dietary behaviors in youth. Health Educ Res 22, 203-206.

39. Power C \& Parsons T (2000) Nutritional and other influences in childhood as predictors of adult obesity. Proc Nutr Soc 59, 267-272.

40. Falkner NH, Neumark-Sztainer D, Story M, Jeffery RW, Beuhring T \& Resnick MD (2001) Social, educational, and psychological correlates of weight status in adolescents. Obes Res 9, 32-42.

41. Food and Agricultural Organization (1998) Country Profile: Mauritania, p. 21. Rome: FAO.

42. Rguibi M \& Belhasen R (2004) Overweight and obesity among urban Sahraoui women of South Morocco. Ethn Dis 14, 542-547.

43. Lahmam A, Baali A, Hilali MK, Cherkaoui M, Chapuis-Lucciani N \& Boetsch G (2008) Obesity, overweight and body-weight perception in a High Atlas Moroccan population. Obes Rev 9, 93-99.

44. Sobal J \& Stunkard AJ (1989) Socioeconomic status and obesity: a review of the literature. Psychol Bull 105, 260-275.

45. Monteiro CA, Conde WL, Lu B \& Popkin BM (2004) Obesity and inequities in health in the developing world. Int J Obes Relat Metab Disord 28, 1181-1186.

46. Mendez MA \& Popkin BM (2004) Globalization, urbanization and nutritional change in the developing world. J Agric Dev Econ 1, 220-241. 